\title{
Efisiensi Teknis Usahatani Tebu Rakyat Dengan Pendekatan Stochasic Frontier di Kabupaten Lampung Utara
}

\section{Technical Efficiency of Sugar Cane Farming with Stochastic Frontier Approach in North Lampung Regency}

\author{
Tri Novi Astuti ${ }^{1 *}$, Fembriarti Erry Prasmatiwi ${ }^{1}$, dan Ktut Murniati ${ }^{1}$ \\ ${ }^{1}$ Universitas Lampung \\ *E-mail : trinoviastuti06@gmail.com
}

\begin{abstract}
This research aims to find out the income of sugar cane farming and to analyze the technical efficiency of sugar cane farming and the factors affecting the technical inefficiency of sugar cane farming in North Lampung Regency. The location was determined purposely (purposive method), considering that North Lampung Regency has been the center of sugar cane production in Lampung Province. The number of the respondents in this study were 35 respondents for plant cane $(P C)$ criteria and 50 respondents for ratoon cane $(R C)$ criteria, respectively, taken by the simple random sampling methods. Data were collected from February to March 2020, taken by interview techniques. The analytical methods used were farm income analysis, stochastic frontier production function and t-test. The study showed that the average income for total cost of sugar cane farming PC and RC criteria were Rp15.308.073,04/hectare and Rp22.310.477,77/hectare. Sugar cane farming in North Lampung Regency was technically efficient with a percentage of 96 percent and 91 percent for PC criteria and RC criteria. For PC criteria, the factors that influence technical inefficiency in sugar cane farming was the level of farmer education and farmer participation in extension activities. For RC criteria, the factors were age and education level of the farmers.
\end{abstract}

Keywords: efficiency, income, sugar cane farming.

Disubmit : 2 Februari $2021 \quad$ Diterima: 7 Juli $2021 \quad$, Disetujui : 29 Oktober 2021

\section{PENDAHULUAN}

Posisi gula sebagai bahan pangan menjadikan komoditas ini memiliki peran penting dalam menjaga ketersediaanya, terlebih lagi Indonedia merupakan salah satu negara produsen gula dan pernah melakukan ekspor gula. Namun, sejak 5 tahun terakhir Indonesia mengalami kekurangan pemenuhan kebutuhan gula dalam negeri dengan rata-rata per tahun sebesar 4.869.443 ton. Kondisi ini mendorong pemerintah untuk mengeluarkan program swasembada gula, guna menjamin ketersedian gula nasional. Upaya pencapaian swasembada gula nasional tidak terlepas dari peran tebu, sebab tebu masih menjadi bahan baku utama produksi gula kristal putih di Indonesia (Pusat Data dan Sistem Informasi Pertanian, 2017).

Menurut Direktorat Jendral Perkebunan (2018), Provinsi Lampung merupakan provinsi dengan produksi dan luas areal tebu terbesar kedua di Indonesia. Pada tahun 2018, sebesar 29,80\% kontribusi Provinsi Lampung terhadap jumlah keseluruhan produksi tebu Indonesia dan sebesar 28,38\% luas areal tebu Indonesia dimiliki oleh Provinsi Lampung. Kabupaten Lampung Utara merupakan salah satu kabupaten di 
Provinsi Lampung yang menjadi sentra produksi tebu perkebunan rakyat dengan tingkat produksi tebu perkebunan rakyat terbesar ketiga di Provinsi Lampung.

Sejak tahun 2014 hingga tahun 2018, rata-rata produktivitas tebu rakyat di Kabupaten Lampung Utara adalah 78,45 ton/ha (PT Buma Cima Nusantara, 2020). Produktivitas tersebut masih di bawah dari produktivitas ideal usahatani tebu, karena idealnya produktivitas tebu baik tebu awal tanam maupun tebu kepras mampu mencapai 100 ton/ha (Pusat Penelitian dan Pengembangan, 2019).

Menurut Mubyarto (1989), tingkat produktivitas yang rendah menandakan bahwa kegiatan usahatani belum efisien secara teknis. Usahatani tebu yang tidak efisien secara teknis dapat disebabkan karena petani belum mampu mengalokasikan input yang dimilikinya untuk menghasilkan output yang maksimal. Usahatani tebu yang tidak efisien secara teknis juga dapat dipengaruhi oleh faktor internal atau faktor yang bersumber dari petani itu sendiri. Faktor-faktor internal yang mempengaruhi inefisiensi teknis usahatani tebu adalah umur petani, tingkat pendidikan petani, pengalaman usahatani dan keikutsertaan petani dalam kegiatan penyuluhan (Setyawati \& Wibowo, 2019). Kegiatan usahatani tebu yang belum efisien secara teknis akan mempengaruhi tingkat pendapatan yang diterima petani.

Kabupaten Lampung Utara merupakan salah satu daerah sentra produksi tebu di Provinsi Lampung. Namun, pada tahun 2016 Kabupaten Lampung Utara memiliki nilai produktivitas terendah dibandingkan kabupaten lainnya. Produktivitas yang rendah menandakan bahwa kegiatan usahatani belum efisien secara teknis. Berdasarkan uraian pendahuluan, maka tujuan dari penelitian ini adalah menghitung pendapatan usahatani tebu rakyat, menganalisis efisiensi teknis usahatani tebu rakyat, dan faktor-faktor yang mempengaruhi inefisiensi teknis usahatani tebu rakyat di Kabupaten Lampung Utara.

\section{METODE PENELITIAN}

Penentuan lokasi penelitian dilakukan secara sengaja (purposive method) (Sutarni et al., 2019) di Kabupaten Lampung Utara dengan pertimbangan bahwa Kabupaten Lampung Utara merupakan salah satu daerah sentra pengembangan produksi tebu di Provinsi Lampung. Berdasarkan pertimbangan tingkat produktivitas tertinggi, maka dipilihlah tiga desa secara sengaja sebagai lokasi penelitian, yaitu Desa Mulyorejo I dan Desa Tulang Bawang Baru di Kecamatan Bunga Mayang serta Desa Penagan Ratu di Kecamatan Abung Timur.

Responden penelitian ini adalah petani tebu rakyat kriteria PC dan kriteria kepras I di Kecamatan Bunga Mayang dan Kecamatan Abung Timur. Pada petani tebu kriteria kepras I penentuan sampel dilakukan dengan menggunakan metode pengambilan sampel secara acak sederhana (simple random sampling). Pengambilan sampel dilakukan dengan cara ditentukan jumlah sampel keseluruhan di ketiga desa yang dijadikan lokasi penelitian, kemudian ditentukan jumlah sampel pada masing-masing desa dan sampel diambil secara acak menggunakan sistem kocokan. Populasi petani tebu rakyat kriteria kepras I di Desa Tulang Bawang Baru, Desa Mulyorejo I, Desa Penagan Ratu adalah 60 petani, 28 petani, dan 57 petani. Sehingga, jumlah populasi petani tebu kriteria kepras I adalah 145 petani. Berdasarkan jumlah populasi tersebut, ditentukan jumlah sampel keseluruhan di lokasi penelitian dengan menggunakan rumus Frank Lynch (Sugiarto et al., 2003) sebagai berikut.

$\mathrm{n}=\frac{\mathrm{NZ} \mathrm{Z}^{2} \mathrm{~s}^{2}}{\mathrm{Nd}^{2}+\mathrm{Z}^{2} \mathrm{~S}^{2}}$

\section{Keterangan:}

$\mathrm{n} \quad=$ Total sampel petani tebu rakyat

$\mathrm{N}=$ Total populasi petani tebu rakyat 
$\mathrm{Z} \quad=$ Selang kepercayaan $(95 \%=1,96)$

$\mathrm{S}^{2}=$ Varian sampel $(5 \%=0,05)$

$\mathrm{d} \quad=$ Derajat penyimpangan $(5 \%=0,05)$

Berdasarkan dari persamaan 1, diperoleh jumlah sampel keseluruhan di lokasi penelitian yaitu 50 petani tebu rakyat kriteria kepras I. Kemudian, ditentukan alokasi proporsi sampel untuk jumlah petani di masing-masing desa dengan rumus berikut:

$\mathrm{na}=\frac{\mathrm{N}_{\mathrm{a}}}{\mathrm{N}_{\mathrm{ab}}} \times \mathrm{n}_{\mathrm{ab}}$

\section{Keterangan:}

na $=$ Total sampel petani desa $\mathrm{A}$

$\mathrm{n}_{\mathrm{ab}}=$ Total sampel keseluruhan

$\mathrm{N}_{\mathrm{a}}=$ Total populasi petani desa A

$\mathrm{N}_{\mathrm{ab}}=$ Total populasi petani keseluruhan (Nazir, 1988)

Berdasarkan persamaan 2, diperoleh jumlah sampel untuk petani tebu rakyat kriteria kepras I di Desa Mulyorejo I, Desa Penagan Ratu, dan Desa tulang Bawang Baru yaitu 20 orang, 10 orang, dan 20 orang. Pada tebu kriteria awal tanam (plant cane) jumlah sampel ditentukan berdasarkan jumlah keseluruhan (populasi) petani tebu rakyat kriteria PC di Desa Mulyorejo I, Desa Penagan Ratu, dan Desa Tulang Bawang Baru pada musim giling tahun 2018/2019, yaitu 9 petani, 19 petani dan 8 petani. Sehingga, diperoleh jumlah sampel keseluruhan untuk petani tebu rakyat kriteria PC adalah 35 petani. Waktu pengumpulan data dilakukan pada bulan Februari 2020-Maret 2020.

Data yang digunakan dalam penelitian ini adalah data primer. Data primer digunakan untuk menghitung pendapatan usahatani tebu rakyat, menganalisis efisiensi teknis dan faktor-faktor yang mempengaruhi inefisiensi teknis usahatani tebu rakyat di Kabupaten Lampung Utara. Data primer tersebut terdiri atas harga gula, harga tetes, rendemen tebu, produksi tebu, biaya pajak lahan, penggunaan dan biaya sarana produksi (lahan, bibit, pupuk, herbisida, dan tenaga kerja), serta identitas petani tebu rakyat (usia, tingkat pendidikan, pengalaman usahatani, dan keikutsertaan kegiatan penyuluhan). Data primer diperoleh dari petani tebu rakyat melalui teknik pengumpulan data, yaitu wawancara dengan menggunakan kuesioner (daftar pertanyaan) yang telah disiapkan.

Analisis data yang digunakan dalam penelitian ini terdiri atas analisis pendapatan untuk menghitung pendapatan usahatani tebu rakyat, model fungsi produksi stochastic frontier untuk menganalisis efisiensi teknis usahatani tebu rakyat, dan uji-t untuk menentukan faktor-faktor yang mempengaruhi inefisiensi teknis usahatani tebu rakyat di Kabupaten Lampung Utara dengan menggunakan program Frontier 4.1c.

Pendapatan merupakan selisih antara penerimaan dalam satu musim tanam dengan biaya total yang dikeluarkan untuk usahatani tebu. Pendapatan dirumuskan sebagai berikut (Suratiyah, 2015):

$\pi=\mathrm{TR}-\mathrm{TC}$

Keterangan:

$\pi \quad=$ Pendapatan $(\mathrm{Rp})$

$\mathrm{TR}=$ Total Revenue $($ penerimaan total $)(\mathrm{Rp})$ 
$\mathrm{TC}=$ Total Cost (biaya total) $(\mathrm{Rp})$

Total Revenue (TR) atau penerimaan total merupakan hasil perkalian antara jumlah hasil produksi atau hasil panen tebu dalam satu musim tanam dengan harga jual tebu dan Total Cost (TC) atau biaya total merupakan penjumlahan seluruh biaya untuk usahatani tebu selama satu musim tanam baik biaya tetap maupun biaya variabel (Suratiyah, 2015).

Efisiensi teknis usahatani tebu dianalisis dengan pendekatan stochastic frontier menggunakan model fungsi produksi stochastic frontier (Utoyo \& Yolandika, 2018). Pendekatan stochastic frontier juga pernah digunakan oleh Noer et all. (2018) untuk menganalisis efisiensi poduksi usahatani padi di Kecamatan Sidomulyo. Model persamaan fungsi produksi stochastic frontier pada usahatani tebu rakyat kriteria PC dalam penelitian ini secara matematis dapat ditulis sebagai berikut (Coelli \& Battese, 1998).

$\mathrm{Ln} \mathrm{D}=\mathrm{b}_{0}+\mathrm{b}_{1} \mathrm{LnI}_{1}+\mathrm{b}_{2} \mathrm{LnI}_{2}+\mathrm{b}_{3} \mathrm{LnI}_{3}+\mathrm{b}_{4} \mathrm{LnI}_{4}+\mathrm{b}_{5} \mathrm{LnI}_{5}+\mathrm{b}_{6} \mathrm{LnI}_{6}+\mathrm{b}_{7} \mathrm{LnI}_{7}+\mathrm{v}_{\mathrm{i}}-\mathrm{u}_{\mathrm{i}}$

Keterangan:

Ln Y $=$ Produksi tebu(kg)

$\mathrm{LnI}_{1}=$ Luas lahan (ha)

$\mathrm{LnI}_{2}=$ Jumlah bibit (batang)

$\mathrm{LnI}_{3}=$ Jumlah pupuk urea $(\mathrm{kg})$

$\mathrm{LnI}_{4}=$ Jumlah pupuk TSP $(\mathrm{kg})$

$\mathrm{LnI}_{5}=$ Jumlah pupuk $\mathrm{KCl}(\mathrm{kg})$

$\mathrm{LnI}_{6}=$ Jumlah pestisida $(\mathrm{gba})$

$\mathrm{LnI}_{7}=$ Tenaga kerja (HKP)

bo $=$ Konstanta

bi $\quad=$ Koefisien regresi, dimana $\mathrm{i}=1,2,3, \ldots \ldots 7$

$\mathrm{v}_{\mathrm{i}}-\mathrm{u}_{\mathrm{i}}=$ Error term (efek inefisiensi di dalam model)

Usahatani tebu kriteria kepras I memiliki model persamaan seperti usahatani tebu kriteria plant cane (PC). Namun, pada usahatani tebu kriteria kepras I tidak memasukkan variabel bibit, dikarenakan bibit yang digunakan berasal dari bibit tanaman sebelumnya. Sehingga, variabel bibit tidak dimasukkan ke dalam persamaan. Efisiensi teknis pada masing-masing petani dapat dihitung dengan menggunakan rumus berikut (Coelli \& Battese, 1998):

$\mathrm{TE}_{\mathrm{i}}=\frac{P_{\mathrm{i}}}{\mathrm{P}_{\mathrm{i}}^{*}}$

Keterangan:

$\mathrm{P}_{\mathrm{i}} \quad=$ Produksi aktual dari pengamatan

$\mathrm{P}_{\mathrm{i}^{*}}=$ Dugaan produksi frontier yang diperoleh dari produksi stochastic frontier.

Analisis faktor-faktor yang mempengaruhi inefisiensi teknis yang digunakan pada penelitian ini mengacu pada model efek inefisiensi teknis yang dikembangkan oleh Coelli and Battese (1998). Faktorfaktor yang mempengaruhi inefisiensi teknis ditentukan dengan uji-t. Adapun persamaannya dapat dituliskan sebagai berikut. 
$\mathrm{u}_{\mathrm{i}}=\mathrm{b}_{0}+\alpha_{1} \mathrm{~J}_{1}+\alpha_{2} \mathrm{~J}_{2}+\alpha_{3} \mathrm{~J}_{3}+\alpha_{4} \mathrm{~J}_{4}$

Keterangan:

$\mathrm{u}_{\mathrm{i}} \quad=$ Efek inefisiensi teknis

$\mathrm{b}_{0} \quad=$ Konstanta

$\mathrm{J}_{1} \quad=$ Umur petani (tahun)

$\mathrm{J}_{2} \quad=$ Tingkat pendidikan (tahun)

$\mathrm{J}_{3} \quad=$ Pengalaman berusahatani (tahun)

$\mathrm{J}_{4} \quad=$ Tidak ikut penyuluhan $=\mathrm{D}_{0}$, Ikut penyuluhan $=\mathrm{D}_{1}$

\section{HASIL DAN PEMBAHASAN}

\section{Analisis Pendapatan Usahatani Tebu Rakyat}

Sarana produksi yang digunakan petani responden untuk berusahatani tebu adalah lahan, bibit, pupuk, herbisida dan tenaga kerja. Penggunaan bibit tebu hanya dibutuhkan untuk tebu kriteria awal tanam atau plant cane (PC). Varietas bibit yang digunakan petani responden adalah BM 9605. Bibit tersebut dibeli petani dari penangkaran bibit petani lain dengan harga Rp471,45/batang tebu.

Petani responden di lokasi penelitian menggunakan 3 jenis pupuk, yaitu pupuk urea, pupuk $\mathrm{KCl}$, dan pupuk TSP. Pupuk yang digunakan petani responden diperoleh dari toko-toko yang menjual sarana produksi dengan harga masing-masing pupuk untuk usahatani tebu kriteria PC, yaitu Rp2.068,57/kg urea, Rp6.091,43/kg KCl, dan Rp6.085,71/kg TSP. Pada usahatani tebu kriteria kepras I, petani responden membeli pupuk urea, pupuk $\mathrm{KCl}$, dan pupuk TSP dengan harga Rp2.016,00/kg urea, Rp6.100,00/kg KCl, dan Rp6.080,00/kg TSP.

Umumnya petani responden menggunakan 2-3 jenis herbisida yang memiliki bahan aktif berbeda beda, seperti diuron, ametrine, 2,4 D, dan paraquat. Serangan gulma, rayutan dan rumput teki di lahan tebu memiliki intensitas yang cukup tinggi. Sehingga, petani responden melakukan pengendalian gulma sebanyak dua kali. Sedangkan, pengendalian hama jarang dilakukan oleh petani responden, karena intensitas serangan hama masih di bawah ambang pengendalian, sehingga tidak mempengaruhi produksi tebu secara signifikan.

Petani responden di lokasi penelitian menggunakan tenaga kerja luar keluarga (TKLK) dan tenaga kerja dalam keluarga (TKDK) untuk menjalankan kegiatan usahatani tebu. Upah yang dibayarkan petani repsonden untuk TKLK adalah Rp40.000/HKP. Selain itu, petani responden di lokasi penelitian juga menggunakan traktor untuk pengolahan lahan dan tenaga hewan untuk melakukan pekerjaan turun tanah serta pembumbunan. Analisis pendapatan usahatani tebu rakyat di Kecamatan Bunga Mayang dan Kecamatan Abung Timur dapat dilihat pada Tabel 1.

Tabel 1. Analisis pendapatan usahatani tebu rakyat per hektar di Kabupaten Lampung Utara

\begin{tabular}{|c|c|c|c|c|c|c|}
\hline \multirow{2}{*}{ No } & \multirow{2}{*}{ Uraian } & \multirow{2}{*}{ Satuan } & \multicolumn{2}{|c|}{ Plant Cane (PC) } & \multicolumn{2}{|c|}{ Kepras I } \\
\hline & & & Jumlah & Nilai (Rp) & Jumlah & Nilai (Rp) \\
\hline \multirow[t]{5}{*}{1} & Penerimaan & & & & & \\
\hline & Produksi Gula (90\%) & $\mathrm{Kg}$ & $3,205.86$ & $32,699,804.73$ & $3,255.09$ & $33,201,871.06$ \\
\hline & Produksi Gula (10\%) & $\mathrm{Kg}$ & 356.21 & $4,132,001.47$ & 361.68 & $4,173,742.83$ \\
\hline & Produksi Tetes & $\mathrm{Kg}$ & $2,358.88$ & $3,066,544.40$ & $2,465.56$ & $3,205,222.22$ \\
\hline & Total Penerimaan & $\mathrm{Rp}$ & & $39,898,350.61$ & & $40,580,836.11$ \\
\hline \multirow[t]{7}{*}{2} & Biaya Produksi & & & & & \\
\hline & I. Biaya Tunai & & & & & \\
\hline & Bibit & Batang & $11,131.27$ & $5,291,854.96$ & - & \\
\hline & Pupuk Urea & $\mathrm{Kg}$ & 344.59 & $700,019.31$ & 340.09 & $685,626.67$ \\
\hline & Pupuk KCl & $\mathrm{Kg}$ & 313.71 & $1,910,921.13$ & 317.41 & $1,936,185.19$ \\
\hline & Pupuk TSP & $\mathrm{Kg}$ & 309.85 & $1,882,090.46$ & 308.15 & $1,873,540.74$ \\
\hline & Biaya Herbisida & $\mathrm{Rp}$ & & $437,731.66$ & & $529,675.93$ \\
\hline
\end{tabular}




\begin{tabular}{|c|c|c|c|c|c|c|}
\hline & Tenaga Kerja Luar Keluarga & HKP & 308.02 & $12,320,675.68$ & 275.38 & $11,015,342.59$ \\
\hline & Pajak & (Rp/tahun) & & $18,069.50$ & & $18,000.00$ \\
\hline & Bunga Modal & $\mathrm{Rp}$ & & $556,285.14$ & & $581,335.09$ \\
\hline & Biaya Karung Gula & $\mathrm{Rp}$ & & $261,455.96$ & & $245,805.83$ \\
\hline & Biaya Asuransi Tangki Tetes & $\mathrm{Rp}$ & & $73,762.19$ & & $77,097.92$ \\
\hline & Total Biaya Tunai & & & $23,452,865.96$ & & $16,962,609.96$ \\
\hline & II. Biaya Diperhitungkan & & & & & \\
\hline & Sewa Lahan & $\mathrm{Rp}$ & & $8,227,799.23$ & & $8,290,740.74$ \\
\hline & Tenaga Kerja Dalam Keluarga & HKP & 9.22 & $368,725.87$ & 7.8 & $311,851.85$ \\
\hline & Penyusutan Alat & $\mathrm{Rp}$ & & $161,730.12$ & & $160,870.54$ \\
\hline & Total Biaya Diperhitungkan & $\mathrm{Rp}$ & & $8,758,255.21$ & & $8,763,463.13$ \\
\hline 3 & III. Total Biaya & $\mathrm{Rp}$ & & $32,211,121.17$ & & $25,726,073.09$ \\
\hline 4 & Pendapatan Kotor Atas Biaya Tunai & $\mathrm{Rp}$ & & $23,861,370.96$ & & $23,973,180.71$ \\
\hline 5 & Biaya Insentif & $\mathrm{Rp}$ & & $1,312,375.40$ & & $1,318,524.94$ \\
\hline 6 & Pendapatan Bersih & & & & & \\
\hline & Pendapatan Atas Biaya Tunai & $\mathrm{Rp}$ & & $15,308,073.04$ & & $22,310,477.77$ \\
\hline & Pendapatan Atas Biaya Total & $\mathrm{Rp}$ & & $6,549,817.82$ & & $13,547,014.64$ \\
\hline 7 & $\mathrm{R} / \mathrm{C}$ & & & & & \\
\hline & I. R/C Atas Biaya Tunai & & & 1.70 & & 2.39 \\
\hline & II. R/C Atas Biaya Total & & & 1.24 & & 1.58 \\
\hline
\end{tabular}

Sumber : Data primer, 2020 (data diolah)

Berdasarkan Tabel 1, penerimaan tertinggi usahatani tebu di Kabupaten Lampung Utara terdapat pada usahatani tebu rakyat kriteria kepras I. Tinggi rendahnya penerimaan dipengaruhi oleh produksi tebu dan rendemen yang diterima petani. Rata-rata produksi usahatani tebu rakyat kriteria PC dan kepras I adalah $78.629,34 \mathrm{~kg} / \mathrm{ha}$ dan $82.185,19 \mathrm{~kg} / \mathrm{ha}$. Rata-rata produksi tebu kriteria kepras I lebih tinggi dibandingkan kriteia PC, hal tersebut dikarenakan jumlah populasi tebu tertinggi berada pada kepras I dan akan mengalami penurunan pada keprasan berikutnya, akibat dari adanya dinamika populasi. Hasil penelitian ini selaras dengan hasil penelitian Gustiana (2017) dan Pranoto et al. (2017).

Menurut Pusat Penelitian Perkebunan Gula Indonesia (2020), produktivitas tebu nasional pada tahun 2019 adalah 69,31 ton/ha (idealnya >100 ton/ha). Angka yang tidak berbeda jauh dari produktivitas tebu dunia yang mencapai 71,15 ton/ha pada tahun 2017 (FAO dalam Kementerian Pertanian, 2019). Rata-rata produktivitas tebu per herktar petani responden di Kabupaten Lampung Utara belum mampu mencapai tingkat produtivitas ideal, namun sudah lebih tinggi dari produktivitas tebu nasional dan internasional.

Biaya produksi yang dikeluarkan oleh petani reponden meliputi biaya tunai dan biaya diperhitungkan. Biaya pembelian bibit (hanya untuk tebu kriteria PC), pupuk urea, pupuk KCl, pupuk TSP, herbisida, upah tenaga kerja luar keluarga, biaya bunga, asuransi tangki tetes, biaya karung dan pajak lahan termasuk kedalam biaya tunai. Sedangkan, upah tenaga kerja dalam keluarga, penyusutan alat-alat pertanian, dan sewa lahan termasuk kedalam biaya diperhitungkan. Selain itu, terdapat biaya yang tidak termasuk ke dalam biaya produksi, yaitu biaya insentif.

Berdasarkan Tabel 1, rata-rata pendapatan per hektar tertinggi petani tebu rakyat di Kecamatan Bunga Mayang dan Kecamatan Abung Timur ada pada tebu kriteria kepras I, yaitu Rp22.310.477,77 untuk pendapatan atas biaya tunai dan Rp13.547.014,64 untuk pendapatan atas biaya total. Hasil penelitian ini selaras dengan hasil penelitian Apriawan et al. (2016) yang menyatakan bahwa pendapatan tertinggi dari produksi gula dan tetes di PT Perkebunan Nusantara VII (Persero) Distrik Bungamayang adalah pada tebu kriteria kepras I.

\section{Efisiensi Teknis Usahatani Tebu Rakyat}

Hasil estimasi fungsi produksi stochastic frontier pada usahatani tebu rakyat kriteria PC dan kepras I di Kabupaten Lampung Utara dapat dilihat pada Tabel 2. 
Tabel 2. Hasil estimasi fungsi produksi stokastik frontier usahatani tebu rakyat di Kabupaten Lampung Utara

\begin{tabular}{lcrrr}
\hline \multirow{2}{*}{ Variabel } & \multicolumn{2}{c}{ Plant Cane $(\mathrm{PC})$} & \multicolumn{2}{c}{ Kepras I } \\
\cline { 2 - 5 } & \multicolumn{1}{c}{ Coefficient } & t-ratio & coefficient & t-ratio \\
\hline Constant & $7,7425^{* * *}$ & 10,3563 & $7,0849 * * *$ & 15,6347 \\
Luas Lahan $\left(\mathrm{I}_{1}\right)$ & $0,3787 * * *$ & 3,3669 & $0,2498^{* * * *}$ & 3,1216 \\
Bibit $\left(\mathrm{I}_{2}\right)$ & $-0,0126$ & $-0,2556$ & - & - \\
Pupuk Urea $\left(\mathrm{I}_{3}\right)$ & $-0,0434$ & $-0,4918$ & 0,0151 & 0,3964 \\
Pupuk KCl $\left(\mathrm{I}_{4}\right)$ & $0,0794 * *$ & 2,7401 & 0,0042 & 0,0556 \\
Pupuk TSP $\left(\mathrm{I}_{5}\right)$ & 0,0277 & 0,6834 & 0,0815 & 0,9092 \\
Herbisida $\left(\mathrm{I}_{6}\right)$ & $-0,0090^{* *}$ & $-2,1057$ & 0,0009 & 0,0994 \\
Tenaga Kerja $\left(\mathrm{I}_{7}\right)$ & $0,5883^{* * *}$ & 8,0093 & $0,6631^{* * * *}$ & 1,1588 \\
Sigma squared & $0,0012^{* * *}$ & 2,2406 & $0,0020 * * *$ & 7,2142 \\
Gamma & $0,9999^{* * *}$ & 44,7826 & $0,9999 * * *$ & 10,6287 \\
\hline Log Likehood Function-OLS & 73,7531 & & 84,6462 & \\
Log Likehood Function-MLE & 85,9307 & & 88,8022 & \\
LR-test & 24,3551 & & 8,3118 & \\
\hline
\end{tabular}

Sumber : Data primer, 2020 (data diolah)

Keterangan :

$*$ = selang kepercayaan $90 \%(\mathrm{t}$-tabel $=1,7138$ dan 1,6848$)$

$* *$ = selang kepercayaan $95 \%$ (t-tabel $=2,0686$ dan 2,0226)

$* * *=$ selang kepercayaan $99 \%(\mathrm{t}$-tabel $=2,8073$ dan 2,7079$)$

Berdasarkan Tabel 2, nilai sigma-squared $\left(\sigma^{2}\right)$ pada usahatani tebu rakyat kriteria PC dan kepras I sebesar 0,0012 dan 0,0020. Nilai tersebut tergolong kecil atau mendekati nol, artinya error term inefisiensi $\left(\mathrm{u}_{\mathrm{i}}\right)$ pada usahatani tebu rakyat di lokasi penelitian terdistribusi secara normal. Nilai gamma ( $\left.\gamma\right)$ pada usahatani tebu rakyat kriteria PC maupun kepras I adalah 0,9999. Nilai tersebut menunjukkan bahwa 99,99\% error yang ada dalam fungsi produksi stochastic frontier disebabkan oleh adanya efek inefisiensi teknis. Nilai log likehood function hasil estimasi dengan metode MLE pada usahatani tebu kriteria PC dan kepras I adalah 85,9307 dan 88,8022 Nilai tersebut lebih besar dibandingkan dengan nilai log likehood function hasil estimasi dengan metode OLS (73,7531 dan 84,6462). Hal tersebut menunjukkan bahwa fungsi produksi dengan metode MLE lebih baik daripada metode OLS dan dapat merepresentasikan kondisi di lokasi penelitian baik pada usahatani tebu rakyat kriteria PC maupun kepras I.

Berdasarkan hasil estimasi, variabel luas lahan dan tenaga kerja berpengaruh nyata terhadap produksi tebu kriteria PC dengan selang kepercayaan 99\% serta pupuk $\mathrm{KCl}$ dan herbisida dengan selang kepercayaan 90\%. Hal ini berarti bahwa dengan penambahan luas lahan sebesar satu persen maka akan meningkatkan produksi tebu sebesar $0,3787 \%$ dan dengan penambahan penggunaan pupuk $\mathrm{KCl}$ dan tenaga kerja sebesar satu persen maka akan meningkatkan produksi tebu sebesar 0,0794\% dan 0,5883\%. Namun, Jika petani menambah penggunaan herbisida sebesar satu persen maka akan menurunkan produksi tebu sebesar $0,0090 \%$. Hal tersebut dikerenakan, petani tebu rakyat telah menggunakan dosis maksimum, jika dosis herbisida ditambah maka bisa berpengaruh pada tanaman tebu itu sendiri atau dapat mengakibatkan tanaman tebu mati. Pada usahatani tebu kriteria kepras I, variabel luas lahan dan tenaga kerja berpengaruh nyata terjadap produksi tebu dengan selang kepercayaan 99\%. Hal tersebut menunjukkan bahwa dengan penambahan luas lahan dan tenaga kerja sebesar satu persen maka akan meningkatkan produksi tebu sebesar $0,2498 \%$ dan $0,6631 \%$. Variabel pupuk urea, pupuk $\mathrm{KCl}$, pupuk TSP, dan herbisida tidak berpeng aruh nyata terhadap produksi tebu kriteria kepras I.

Penggunaan pupuk urea dan pupuk TSP tidak berpengaruh nyata terhadap produksi tebu kriteria PC dan kepras I dikarenakan dosis yang digunakan belum memenuhi dosis anjuran. Selain itu, bibit tebu juga tidak berpengaruh nyata terhadap produksi tebu dikarenakan varietas bibit yang digunakan oleh petani tebu 
rakyat di lokasi penelitian tidak tahan terhadap kekeringan, sehingga menyebabkan tanaman tebu petani mati akibat musim kemarau pada musim giling tahun 2018/1019. Hasil penelitian ini selaras dengan penelitian Setyawati \& Wibowo (2019) bahwa bibit tidak memliki pengaruh terhadap produksi tebu. Penggunaan herbisida tidak berpengaruh nyata terhadap produksi tebu kriteria kepras I dikarenakan pengendalian gulma juga dilakukan saat kegiatan pengeprasan dan klentek, sehingga dapat mengurangi populasi gulma. Hasil penelitian ini selaras dengan penelitian Susilowati \& Tinaprilla (2020).

Sebaran efisiensi teknis usahatani tebu rakyat dapat diketahui berdasarkan nilai indeks efisiensi teknis hasil analisis, dimana nilai indek efisiensi teknis dikategorikan menjadi tiga yaitu belum efisien jika bernilai $\leq 0,7$, cukup efisien jika bernilai 0,70-0,90, dan sangat efisien jika bernilai > 0,90 (Coelli \& Battese, 1998). Sebaran efisiensi teknis usahatani tebu rakyat kriteria PC dan kepras I di Kecamatan Bunga Mayang dan Kecamatan Abung Timur dapat dilihat pada Tabel 3.

Tabel 3. Sebaran efisiensi teknis usahatani tebu rakyat kriteria PC dan kepras I di Kabupaten Lampung Utara

\begin{tabular}{|c|c|c|c|c|}
\hline \multirow[b]{2}{*}{ Efisiensi Teknis } & \multicolumn{2}{|c|}{ Plant Cane (PC) } & \multicolumn{2}{|c|}{ Kepras I } \\
\hline & $\begin{array}{l}\text { Jumlah } \\
\text { (orang) }\end{array}$ & $\begin{array}{c}\text { Persentase } \\
(\%)\end{array}$ & $\begin{array}{l}\text { Jumlah } \\
\text { (orang) }\end{array}$ & $\begin{array}{c}\text { Persentase } \\
(\%)\end{array}$ \\
\hline$<0,70$ & 0 & 0,00 & 0 & 0,00 \\
\hline $0,70-0,90$ & 1 & 2,86 & 20 & 40,00 \\
\hline$>0,90$ & 34 & 97,14 & 30 & 60,00 \\
\hline Jumlah & 35 & 100,00 & 50 & 100,00 \\
\hline Rata-rata & 0,96 & - & 0,91 & - \\
\hline Minimum & 0,88 & - & 0,80 & - \\
\hline Maksimum & 0,99 & - & 0,99 & - \\
\hline
\end{tabular}

Sumber : Data primer, 2020 (data diolah)

Berdasarkan Tabel 3, sebesar 2,86\% dan 40,00\% petani tebu rakyat kriteria PC dan kepras I termasuk dalam kategori cukup efisien. Sebesar $97,14 \%$ dan $60,00 \%$ petani tebu rakyat kriteria PC dan kepras I termasuk ke dalam kategori sangat efisien. Rata-rata efisiensi teknis usahatani tebu rakyat kriteria PC lebih besar dibandingkan kriteria kepras I, yaitu 0,96. Hal tersebut menandakan bahwa usahatani tebu rakyat kriteria PC lebih efisien secara teknis dibandingkan usahatani tebu rakyat kriteria kepras I. Kondisi ini menunjukan bahwa,semakin rendah nilai efisiensi maka semakin tinggi tingkat frekuensi keprasannya. Hasil penelitian ini selaras dengan penelitian Setyawati \& Wibowo (2019).

\section{Analisis Faktor-Faktor yang Mempengaruhi Inefisiensi Teknis Usahatani Tebu Rakyat}

Analisis inefisiensi teknis usahatani tebu rakyat dianalisis menggunakan model efek inefisiensi teknis dari fungsi produksi stokastik frontier. Faktor-faktor yang diduga sebagai faktor inefisiensi teknis adalah umur petani, tingkat pendidikan, pengalaman berusahatani tebu, dan keikutsertaan petani dalam kegiatan penyuluhan tebu (Husyairi, 2012). Hasil pendugaan faktor-faktor yang mempengaruhi inefisiensi teknis usahatani tebu rakyat kriteria PC dan kepras I di Kecamatan Bunga Mayang dan Kecamatan Abung Timur dapat dilihat pada Tabel 4.

Tabel 4. Hasil pendugaan faktor-faktor yang mempengaruhi inefisiensi teknis usahatani tebu rakyat di Kabupaten Lampung Utara

\begin{tabular}{llrrr}
\hline \multirow{2}{*}{ Variabel } & \multicolumn{2}{c}{ Plant Cane (PC) } & \multicolumn{2}{c}{ Kepras I } \\
\cline { 2 - 5 } & \multicolumn{1}{c}{ Koefisien } & t-rasio & Koefisien & \multicolumn{1}{c}{ t-rasio } \\
\hline Constant & $7,7425^{* * *}$ & 10,3563 & $7,0849^{* * *}$ & 15,6347 \\
Umur Petani (J1) & 0,0003 & 0,3828 & $0,0015^{* * *}$ & 2,7668 \\
Tingkat Pendidikan (J2) & $0,0053^{* *}$ & 2,1756 & $0,0050^{* *}$ & 2,4429 \\
Pengalaman Berusahatani Tebu (J3) & $-0,0011$ & $-0,6020$ & $-0,0015$ & $-1,0556$
\end{tabular}

Volume 5 Nomor 2,Oktober Tahun 2021 | 163 
Keikutsertaan Kegiatan Penyuluhan (J4)

Sumber : Data primer, 2020 (data diolah)

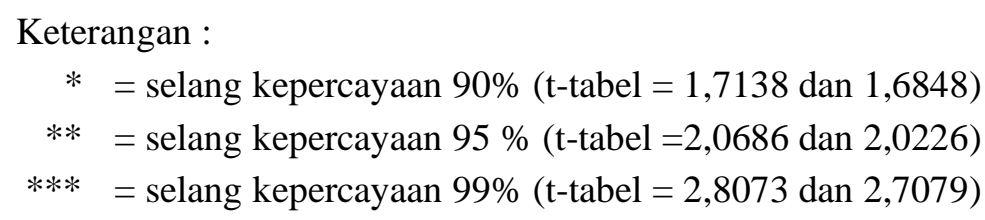

Berdasarkan Tabel 4, diketahui bahwa variabel pendidikan berpengaruh nyata dengan tanda positif. Hal tersebut menunjukkan bahwa semakin tinggi tingkat pendidikan petani akan meningkatkan inefisiesi teknis. Keikutsertaan petani dalam kegiatan penyuluhan berpengaruh nyata dengan tanda negatif yang berarti bahwa kegiatan penyuluhan dapat menurunkan inefisiensi teknis usahatani tebu rakyat. Variabel umur dan pengalaman petani dalam berusahatani tebu tidak berpengaruh nyata terhadap tingkat inefisiensi teknis usahatani tebu rakyat kriteria PC.

Variabel umur petani tebu berpengaruh nyata dengan tanda positif pada usahatani tebu rakyat kriteria kepras I, hal tersebut menunjukkan semakin tua umur petani dapat meningkatkan inefisiensi teknis. Tingkat pendidikan petani berpengaruh nyata dengan tanda positif yang berarti bahwa semakin tinggi tingkat pendidikan petani dapat meningkatkan inefisiensi teknis usahatani tebu rakyat kriteria kepras I. Variabel pengalaman petani dalam berusahatani tebu tidak berpengaruh nyata terhadap tingkat inefisiensi teknis usahatani tebu rakyat di lokasi penelitian. Hal tersebut dikarenakan, petani yang memiliki pengalaman lebih banyak adalah orang yang berusia lanjut, sehingga kegiatan usahatani tebu yang dilakukannya dikerjakan oleh orang lain. Hasil penelitian ini selaras dengan penelitian (Zainuddin \& Wibowo, 2018). Keikutsertaan petani dalam kegiatan penyuluhan juga tidak berpengaruh nyata terhadap tingkat inefisiensi teknis usahatani tebu rakyat kriteria kepras I. Hal tersebut dikarenakan, sebagian besar petani tebu rakyat kriteria kepras I tidak mengikuti kegiatan penyuluhan, yaitu sebesar 52,00\%.

\section{KESIMPULAN DAN SARAN}

Jumlah pendapatan usahatani tebu rakyat kriteria PC dan kepras I di Kabupaten Lampung Utara adalah Rp15.308.073,04 per hektar dan Rp22.310.477,77 per hektar. Usahatani tebu rakyat di Kabupaten Lampung Utara baik kriteria PC maupun kepras I sudah efisien secara teknis. Faktor-faktor yang mempengaruhi inefesiensi teknis usahatani tebu kriteria PC adalah tingkat pendidikan petani dan keikutsertaan petani tebu dalam kegiatan penyuluhan. Pada usahatani tebu kriteria kepras I, umur petani tebu dan tingkat pendidikan petani menjadi faktor-faktor yang mempengaruhi inefesiensi teknis usahatani tebu.

Petani tebu rakyat diharapkan dapat melakukan perawatan tebu sesuai dengan anjuran perusahaan, seperti melakukan pemupukan dan klentek sebanyak dua kali, serta memuat tebu dengan posisi yang benar sehingga sampel tebu yang dianalisis di core sample dapat merepresentasikan rendemen tebu yang sebenarnya.

\section{DAFTAR PUSTAKA}

Apriawan, D. C., Irham, I., \& Mulyo, J. H. (2016). Analisis Produksi Tebu Dan Gula Di Pt. Perkebunan Nusantara Vii (Persero). Agro Ekonomi, 26(2), 159. https://doi.org/10.22146/agroekonomi.17268

Coelli, T and Battese, G. (1998). An introduction to efficiency and productivity analysis. Kluwer Academic. 
Astuti : Efisiensi Teknis Usahatani Tebu Rakyat dengan

Direktorat Jendral Perkebunan. (2018). Produksi Tebu Menurut Provinsi di Indonesia, 2015-2018.

Gustiana, E. (2017). Analisis Pendapatan dan Distribusi Pendapatan Usahatani Tebu Rakyat di Kecamatan Bunga Mayang, Kabupaten Lampung Utara. Universitas Lampung.

Husyairi, K. (2012). Analisis Efisiensi Produksi Tebu Rakyat Di Wilayah Kerja PTPN VII Unit Usaha Bungamayang Kabupaten Lampung Utara Propinsi Lampung. Institut Pertanian Bogor.

Kementerian Pertanian. (2019). Outlook Komoditas Perkebunan Tebu. Kementerian Pertanian.

Mubyarto. (1989). Pengantar Ekonomi Pertanian. LP3ES.

Nazir M. (1988). Metode Penelitian. Ghalia Indonesia.

Noer, S. R., Zakaria, W. A., \& Murniati, K. (2018). Analisis Efisiensi Produksi Usahatani Padi Ladang Di Kecamatan Sidomulyo Kabupaten Lampung Selatan. Jurnal Ilmu-Ilmu Agribisnis, 6(1), 17. https://doi.org/10.23960/jiia.v6i1.17-24

Pranoto, I. L., Lestari, D. A. H., \& Murniati, K. (2017). The Evaluation of Partnership Between The Sugarcane Farmers and PT Perkebunan Nusantara VII Business Unit Bunga Mayang, Bunga Mayang District, North Lampung Regency. Jurnal Ilmu-Ilmu Agribisnis, 5(4), 376-383.

PT Buma Cima Nusantara. (2020). Rencana Kerja dan Anggaran Perusahaan 2020.

Pusat Data dan Sistem Informasi Pertanian. (2017). Basis Data Konsumsi Pangan.

Pusat Penelitian dan Pengembangan. (2019). Rawat Ratoon Tebu.

Pusat Penelitian Perkebunan Gula Indonesia. (2020). Taksasi Produksi Tebu.

Setyawati, I. K., \& Wibowo, R. (2019). EFISIENSI TEKNIS PRODUKSI USAHATANI TEBU PLANT

CANE DAN TEBU RATOON CANE (Studi Kasus di PT. Perkebunan Nusantara X). JSEP (Journal of Social and Agricultural Economics), 12(1), 80. https://doi.org/10.19184/jsep.v12i1.9950

Sugiarto, Dergibson S, Lasmono TS, dan D. S. (2003). Teknik Sampling. Gramedia Pustaka Utama.

Suratiyah, K. (2015). Ilmu Usahatani. Penebar Swadaya.

Susilowati, Sri Hery., Tinaprilla, N. (2020). Analisis Efisiensi Usaha Tani Tebu Di Jawa Timur. Jurnal Penelitian Tanaman Industri, 18(4), 162. https://doi.org/10.21082/jlittri.v18n4.2012.162-172

Sutarni, S., Irawati, L., Unteawati, B., \& Yolandika, C. (2019). Proses Pengambilan Keputusan Pembelian Sayuran Hidroponik Di Kota Bandar Lampung. Journal of Food System \& Agribusiness, 2(1), 17-24. https://doi.org/10.25181/jofsa.v2i1.1107

Utoyo, B., \& Yolandika, C. (2018). Technical Efficiency of Palm Oil Plantation in Lampung, Indonesia. International Journal of Sustainable Biomass and Bioenergy, 1-5.

Zainuddin, A., \& Wibowo, R. (2018). Analisis Potensi Produksi Tebu dengan Pendekatan Fungsi Produksi Frontir di PT Perkebunan Nusantara X. Jurnal Pangan, 27(1), 33-42. 